\title{
Quality of life and coping strategies of outpatients with a depressive disorder in maintenance therapy - a cross-sectional study
}

This article was published in the following Dove Press journal:

Neuropsychiatric Disease and Treatment

\author{
Michaela Holubova ${ }^{1,2}$ \\ Jan Prasko' \\ Marie Ociskova' \\ Ales Grambal' \\ Milos Slepecky \\ Marketa Marackova' \\ Dana Kamaradova' \\ Marta Zatkova ${ }^{3}$ \\ 'Department of Psychiatry, Faculty \\ of Medicine and Dentistry, Palacky \\ University Olomouc, University \\ Hospital Olomouc, Olomouc, \\ ${ }^{2}$ Department of Psychiatry, Hospital \\ Liberec, Liberec, Czech Republic; \\ ${ }^{3}$ Department of Psychology Sciences, \\ Faculty of Social Science and Health \\ Care, Constantine the Philosopher \\ University in Nitra, Nitra-Chrenova, \\ Slovak Republic
}

Background: The quality of life (QoL) is a multidimensional view that represents all aspects of patient well-being in various areas of patient life. Specific coping strategies may be connected to both the QoL and the severity of mental disorder. The aim of this investigation was to examine the relationship between the QoL and the coping strategies of outpatients with a depressive disorder.

Methods: Eighty-two outpatients, who met the criteria of the International Classification of Diseases, Tenth Revision, for a depressive disorder, were enrolled in the cross-sectional study. Data on sociodemographic and clinical variables were obtained from the medical records. Individuals filled the following standardized questionnaires: Quality of Life Satisfaction and Enjoyment Questionnaire, Stress Coping Style Questionnaire, and Clinical Global Impression. Multiple regression analyses with backward elimination were performed to discover the most influential factors contributing to QoL.

Results: The participants with a depressive disorder showed an overuse of negative coping strategies, especially escape tendency and resignation. A positive self-instruction strategy was used by the patients less often. The coping strategies were significantly associated with the QoL. A more frequent use of positive coping strategies had a positive association with the QoL. The main factors related to QoL were the subjective severity of the disorder, employment, and positive coping strategies.

Conclusion: The study confirmed the relationship between QoL and the coping strategies of outpatients with a depressive disorder.

Keywords: coping strategies, quality of life, depressive disorder

\section{Introduction}

Quality of life (QoL) represents an individual's satisfaction and functioning in various areas of life including physical, psychological, social, and environmental (cultural) areas. Its improvement is the main goal of the health care provided in recent decades. ${ }^{1}$

Some research studies indicate reduced QoL in patients with a depressive disorder. ${ }^{2-6}$ Several studies have showed that severity of the symptoms negatively impacts the QoL of the patients with major depression. ${ }^{7,8}$ Although QoL is improved by proper treatment, it tends to remain reduced compared with healthy controls. ${ }^{8,9}$ Furthermore, reduced QoL persists even after a year of monitoring, especially in patients who are not in remission. ${ }^{9}$

Coping is a process of handling the external or internal stress that is reflected as difficult or exceeding own resources. Preferred coping strategies are somewhat stable
Correspondence: Jan Prasko Department of Psychiatry, University Hospital Olomouc FNOL, I.P.Pavlova 185/6, Olomouc 779 00, Czech Republic Tel +42058 8443519

Email praskojan@seznam.cz 
in time and are used in a broad range of stressful situations. ${ }^{10}$ Specific patterns of coping strategies may affect the shortterm and the long-term course of a mental disorder. ${ }^{11}$ Coping depends on the intensity of stress, nature of the stressful life events, and personal characteristics such as age, gender, intelligence, and personality and its resources, ${ }^{12}$ which together have an impact on the depressive symptoms, the course of depression, the quality of remission, and the outcome of the disorder. $^{13}$

Coping strategies can be divided into several categories. Folkman et al defined two essential functions of coping strategies, emotion-focused and problem-focused. ${ }^{14}$ Compas et al distinguished between active and avoidant coping strategies. ${ }^{15}$ Active coping represents protective strategies based on an active pursuit to mitigate or eliminate the $\operatorname{stress}^{16}$ and is related to lower anxiety, stress, and depressive symptoms. ${ }^{17}$ Active coping is more efficient in the adjustment to chronic stress than the avoidant one. ${ }^{18}$ During the avoidant coping, an individual does not reach out to sort the source of the stress and instead tries to lower own negative emotional reactions. Because the origin of the stress has not been eliminated, the negative emotions keep turning up. ${ }^{12}$ Passive avoidance predicts depressive symptoms. ${ }^{19}$ In this study, we use the terms positive (adaptive) and negative (maladaptive) coping strategies. Adaptive coping is considered to be efficient, and maladaptive coping reflects the noneffective handling of stressful situations. ${ }^{20}$

Individuals who adaptively cope with stress use primarily positive reappraisal (reframing) of stressful situations, goaldirected problem-focused coping strategies, and spiritual or transcendent beliefs to seek peace and calm; they give meaning into ordinary events of daily life in order to gain a psychological distance from distress, and exhibit characteristics such as flexibility to unexpected changes in life, ability to seek social support, perceiving stress as a challenge, existing in harmony with nature, optimism, and sense of humor, work, and love. ${ }^{21}$ Development of psychiatric disorder may negatively decrease these adaptive capacities. ${ }^{16,22}$ Participants with depression become more focused on the past mistakes and the future failures than healthy persons, which may lower adaptive coping in the presence. ${ }^{23}$

The topics of the QoL, depressive disorders, and coping strategies are interrelated. ${ }^{3}$ The negative symptoms of the disorder have a significant impact on the QoL. ${ }^{24}$ Long-term use of negative coping strategies may intensify the depressive disorder and lead to an overall reduction of QoL. Similarly, a long-term reduction of the QoL along with the use of negative coping strategies may be a precursor to the development of depressive disorders. ${ }^{25,26}$ The development of a depressive disorder has been connected with maladaptive stress management and failure to cope with stressful life events. ${ }^{27}$ Stress and coping have also been found to be firmly connected with the QoL of participants with anxiety and depressive disorders. ${ }^{28}$

The present investigation examines the coping strategies, the QoL, and the relationship between these variables in the patients suffering from depressive disorders. The study hypotheses were as follows:

1) The level of the QoL positively correlates with positive coping strategies and negatively with negative coping strategies.

2) The QoL correlates negatively with the severity of the disorder.

\section{Methods}

The research group consisted of outpatients with a depressive disorder diagnosed according to the International Classification of Diseases, Tenth Revision. ${ }^{29}$ The data collection took place between March 2014 and November 2015. Collaborative psychiatrists from different Czech cities offered the questionnaires to their outpatients during a regular medical control. Inclusion criteria were as follows: age between 18 and 60 years; willing to provide signed informed consent; and stabilized phase of the mental illness at the time of assessment (patients in remission of the disorder, came to normal control without the need for the change of treatment strategy, on maintenance antidepressant treatment). The outpatients with severe acute symptomatology (ie, with a need for the modification of the therapeutic strategy), or the patients who needed a hospitalization or with substance abuse were not enrolled in the study.

\section{Assessments}

During a routine psychiatric control, the outpatients filled the following questionnaires.

\section{Stress Coping Style Questionnaire (SVF-78)}

This questionnaire contains 78 items divided into 13 subscales, each demonstrating a particular way of reacting to a stressful situation. ${ }^{20}$ The questionnaire evaluates the coping style (positive/negative) of a person and measures the rate of use of the coping style by the person in everyday life using the $T$-score range of maladaptive/adaptive coping and efficient use of coping style. The questionnaire monitor the basic coping styles and specific coping strategies in more detail. These strategies are divided to the positive and the negative 
styles of coping. The average use of the coping strategies is indicated by a $T$-score between 40 and 60. A $T$-score higher than 60 indicates a higher use of coping strategies, while as score lower than 40 indicates a reduced use of an appropriate strategy. In the case of positive strategies, a $T$-score higher than 60 is an indicator of their adaptive use, while in the case of negative coping strategies, a $T$-score higher than 60 indicates the maladaptive use of these strategies. Negative strategies comprise escape tendency, perseveration, resignation, and self-accusation, while positive strategies include underestimation, guilt denial, diversion, compensatory satisfaction, situation control, reaction control, and positive self-instruction. ${ }^{20}$ The SVF-78 was standardized in the Czech population, and the Cronbach's alpha of Czech version was between 0.77 and $0.94 .^{30}$

Quality of Life Satisfaction and Enjoyment (Q-LES-Q) This questionnaire comprises 93 items divided into eight domains of QoL. ${ }^{31}$ The participants assessed each domain by choosing one number from a five-point Likert scale according to their level of satisfaction with the covered area, compared to their experience during the previous week. The domains included physical health, feelings, leisure, household, work, school/study, social relations, general, and sum of Q-LES-Q. The Czech version of the Q-LES-Q was validated by Müllerova. ${ }^{32}$ The analyses indicated a high internal consistency (Cronbach's alpha $=0.8-0.9) .{ }^{33}$ The summary ratings were found to be reliable and valid in a group of depressed outpatients. ${ }^{33}$

\section{Clinical Global Impression (CGI)}

This tool is used for global evaluation of the severity of a disorder, which uses a 7-point scale ranging from 1 (normal) to 7 (among the most extremely ill people), and is based on the symptoms, behaviors, and functioning over the last seven days. ${ }^{34}$ The objective evaluation is performed by a trained rater - a psychologist or a psychiatrist (objCGI-S), whereas the subjective assessment is carried out by the patients themselves (subjCGI-S). The internal reliability of the scale is satisfactory. The intra-class correlations were in the interval of $0.88-0.92 . .^{35}$

\section{Demographic questionnaire}

This questionnaire inquired gender, age, age at the onset of disorder, length of the treatment, marital status, education, employment status, retirement or disability benefits, number of past visited psychiatrists, number of previous hospitalizations, current medication, withdrawal medication in the past (recommended by a psychiatrist or arbitrary), number of siblings, and positive family history.

\section{Statistical analysis and ethical approval}

Statistics were calculated using statistical software SPSS 24.0 and the Prism (GraphPad Prism version 5.0; http://www. graphpad.com/prism/prism.htm). Patient's demographic and clinical characteristics were analyzed using column statistics. The Shapiro-Wilk $W$ test was used to determine the normal distribution of the demographic, SVF-78, Q-LES-Q, and subjCGI/objCGI variables. For the analysis of the categorical data, the chi-square or Fisher's exact test was used. The interactions between variables with a normal distribution were calculated using Pearson's correlation analysis, while Spearman's rank correlation was used for variables with non-normal distribution. In addition, multiple regression analysis was applied. The level of significance was determined at $5 \%$.

The local ethics committee of the University Hospital Olomouc approved the study. The investigation was conducted in agreement with the latest version of the Declaration of Helsinki and standards of Good Clinical Practice. ${ }^{36}$ All the participants signed an informed consent.

\section{Results Sample description}

Eighty-one outpatients with a depressive disorder were enrolled in the study and included in the statistical analysis. The most frequent diagnosis was a major depressive disorder $(n=42)$, followed by recurrent depressive disorder $(n=36)$ and persistent affective disorder - dysthymia $(n=3)$. Minimum duration of the illness was one year, and the most prolonged duration was 49 years. Thirty-six percent of the participants reported a psychiatric family burden. Most participants were married (54.3\%), and had secondary school education (49.4\%). The demographic and clinical characteristics of the sample are presented in Table 1 .

\section{Current medication}

Seventy-six patients (93.8\%) reported that they used prescribed antidepressive medication, and the remaining $6.2 \%$ of the participants did not specify whether and how regularly they were taking the prescribed medication. The majority of patients $(91.3 \%)$ indicated that they used the medication in prescribed dosage regularly, and four participants (4.9\%) described taking the medication irregularly (they had forgotten to use it sometimes). The type and the dosage of the medication were not monitored in this study. 
Table I Description of the sample: demographic and clinical data

\begin{tabular}{ll}
\hline Variables & Frequencies \\
& or mean \pm SD \\
\hline Gender (M:F) & $19: 62$ \\
Age (years) & $52.1 \pm 13.6$ \\
Age of disease onset (years) & $42.3 \pm 12.8$ \\
Lifetime duration of treatment (years) & $10.5 \pm 10.0$ \\
Number of hospitalizations & $0.5 \pm 1.1$ \\
Psychiatric heredity & 29 \\
Same disorder & 14 \\
Other disorders & 15 \\
Without & 52 \\
Education & \\
Elementary & 5 \\
Vocational training & 19 \\
Secondary school & 40 \\
University & 17 \\
Marital status & \\
Single & 11 \\
Married & 44 \\
Divorced & 21 \\
Widowed & 2 \\
Incomplete data & 3 \\
Partner & \\
No & 24 \\
Yes & 34 \\
Incomplete data & 3 \\
Employment & \\
No & \\
Yes & \\
Incomplete data & 36 \\
\hline & \\
\hline
\end{tabular}

Abbrevations: $F$, female; $M$, male.

\section{Severity of the disorder}

The severity of psychopathology was evaluated by a psychiatrist using the objCGI-S scores. The average ObjCGI-S score was $3.2 \pm 1.3$; it means that psychiatrists assessed the actual severity of their outpatients as mild in average. The average subjCGI-S score was $2.5 \pm 1.2$. The difference between the psychiatrist-evaluated and patient-evaluated scores was $0.7 \pm 1.0$ points. The subjective and objective assessment of the severity of psychopathology strongly correlated (Pearson's $r=0.66 ; p<0.001$ ).

\section{Coping strategies}

The coping strategy questionnaire SVF-78 was completed by a total of 80 participants. The participants reported average use of the positive coping strategies as indicated by an average range of $T$-scores. The patients used the positive strategy of guilt denial ("It is not my responsibility that the stressful situation occurred") and reaction control ("I try to be in control of my reactions"). Among the positive strategies used by the participants, the strategy positive self-instruction was used less often (attribution of competence and control
Table 2 Mean scores of positive coping strategies according to SVF-78

\begin{tabular}{ll}
\hline Positive coping strategies & Mean \pm SD \\
\hline Underestimation & $45.9 \pm 10.8$ \\
Guilt denial & $54.2 \pm 11.3$ \\
Diversion & $49.2 \pm 10.5$ \\
Alternative satisfaction & $49.6 \pm 10.9$ \\
Situation control & $47.5 \pm 11.9$ \\
Reaction control & $51.2 \pm 10.4$ \\
Positive self-instruction & $42.6 \pm 11.2$ \\
Need for social support & a \\
Using of positive coping & $49.5 \pm 10.1$ \\
\hline
\end{tabular}

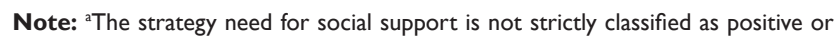
negative.

Abbreviation: SVF-78, Stress Coping Style Questionnaire.

over the situation, including self-support of their own), but still within the range of average use (Table 2).

The patients used negative coping strategies more often than the positive ones (indicated by an average $T$-score of 60 or more). They tended to use mainly escape tendency (a trend towards escape from stressful situations) and resignation (give up with feelings of helplessness and hopelessness in dealing with the situation) in stressful situations. The active avoidance (efforts to reduce and avoid stressful situations) strategy, which is not included in positive or negative coping strategies (it depends on the personality and the context of the situation), was also used often (Table 3).

\section{Relationship between coping strategies and demographic and clinical variables}

The relation between individual coping strategies and demographic and clinical variables was examined (Table 4). The positive coping strategies were moderately negatively related to the subjective severity of psychopathology (subjCGI-S). All of the negative coping strategies (escape tendency, perseveration, resignation, and self-accusation) were positively

Table 3 Mean scores of negative coping strategies according to SVF-78

\begin{tabular}{ll}
\hline Negative coping strategies & Mean \pm SD \\
\hline Active avoidance $^{\mathrm{a}}$ & $57.6 \pm 8.9$ \\
Escape tendency & $59.9 \pm 9.1$ \\
Perseveration & $56.0 \pm 9.0$ \\
Resignation & $58.9 \pm 10.6$ \\
Self-accusation & $54.6 \pm 10.9$ \\
Using of negative coping & $60.4 \pm 10.3$ \\
\hline
\end{tabular}

Note: ${ }^{2}$ The strategy active avoidance is not strictly classified as positive or negative. Abbreviation: SVF-78, Stress Coping Style Questionnaire. 
Table 4 Relationship between coping strategies and demographic and clinical variables

\begin{tabular}{|c|c|c|c|c|c|}
\hline Domain & Age & Onset & Length & objCGI & subjCGI \\
\hline Underestimation & $0.23 *$ & 0.22 & -0.09 & -0.20 & $-0.32 * *$ \\
\hline Guilt denial & 0.09 & 0.08 & -0.08 & -0.13 & $-0.22^{*}$ \\
\hline Diversion & -0.03 & 0.07 & $-0.24^{*}$ & -0.15 & $-0.23 *$ \\
\hline Compensatory satisfaction & 0.004 & 0.05 & -0.13 & -0.12 & -0.18 \\
\hline Situation control & 0.05 & 0.01 & -0.06 & $-0.30 * *$ & $-0.26 *$ \\
\hline Reaction control & 0.10 & 0.05 & -0.07 & -0.20 & $-0.24^{*}$ \\
\hline Positive self-instruction & 0.14 & 0.18 & -0.15 & -0.17 & $-0.26 *$ \\
\hline Need for social support & -0.13 & -0.14 & -0.04 & -0.07 & -0.07 \\
\hline Active avoidance & 0.06 & -0.07 & -0.002 & -0.01 & 0.02 \\
\hline Escape tendency & 0.14 & 0.19 & -0.16 & 0.19 & $0.25^{*}$ \\
\hline Perseveration & -0.03 & -0.09 & 0.08 & 0.17 & $0.24^{*}$ \\
\hline Resignation & -0.002 & -0.02 & -0.02 & $0.22 *$ & $0.29 * *$ \\
\hline Self-accusation & -0.16 & -0.12 & 0.03 & 0.15 & $0.27^{*}$ \\
\hline Negative coping & -0.01 & -0.01 & -0.01 & $0.25^{*}$ & $0.36 * *$ \\
\hline Positive coping & 0.13 & 0.17 & -0.19 & $-0.24^{*}$ & $-0.32 * *$ \\
\hline
\end{tabular}

Note: $*_{p}<0.05,{ }^{*} p<0.01$, statistically significant data shown in bold.

Abbreviations: objCGI, (Clinical Global Impression) - objective; subjCGI, (Clinical Global Impression) - subjective.

related to the subjCGI-S score. The objCGI was linked only to the situation control (positive coping) and resignation (negative coping) (Table 4).

\section{Quality of life}

A total of eighty participants completed Q-LES-Q. Their scores reached $280.9 \pm 59.9$ out of the maximum of 465 possible points, wherein the total level of QoL reached $60.4 \%$, slightly more than the average level of QoL. The QoL of the patients was notably lower in the domains feelings, work, leisure time, social activities, and general of Q-LES-Q. The QoL was the highest in the household domain, followed by the leisure and feelings domains (Table 5).

\section{Relation between the QoL and demographic and clinical variables}

Most of the domains of Q-LES-Q correlated negatively with the objective and subjective evaluation of severity of the disorder (objCG-S and subjCGI-S) but not with other

Table 5 Quality of life in each domain (points/percentage)

\begin{tabular}{ll}
\hline Physical health (maximum 65 points) & $39.5 \pm 9.9(60.8)$ \\
Feelings (maximum 70 points) & $48.0 \pm 10.6(68.5)$ \\
Work (maximum 65 points) & $35.9 \pm 19.4(55.2)$ \\
Household (maximum 50 points) & $36.8 \pm 10.0(73.5)$ \\
School/study (maximum 50 points) & $12.8 \pm 8.1(25.6)$ \\
Leisure (maximum 30 points) & $20.8 \pm 5.5(69.3)$ \\
Social activities (maximum 55 points) & $36.5 \pm 9.1(66.3)$ \\
General (maximum 80 points) & $50.8 \pm I I .8(63.5)$ \\
Sum of Q-LES-Q (maximum 465 points) & $280.9 \pm 59.9(60.4)$ \\
\hline
\end{tabular}

Abbreviation: Q-LES-Q, Quality of Life Satisfaction and Enjoyment Questionnaire. clinical or demographic variables (such as age, onset of the disorder, duration), except the number of hospitalizations which correlated negatively with domains physical health, work, leisure time, social activities, general, and with sum of Q-LES-Q. The feeling of greater severity of the disorder had a negative relation especially with physical health, feelings, and functioning in the household (Table 6).

\section{Relation between the QoL and coping strategies \\ Positive coping and QoL}

Positive coping strategies were positively associated with the overall QoL of patients with depression in the majority of Q-LES-Q domains excluding the school. The most strongly

Table 6 Correlations between quality of life and demographic or clinical variables

\begin{tabular}{|c|c|c|c|}
\hline Domains & objCGI & subjCGI & $\begin{array}{l}\text { Number of } \\
\text { hospitalizations }\end{array}$ \\
\hline Physical health & $-0.45^{\mathrm{s}, * * *}$ & $-0.63^{\mathrm{s}, * * *}$ & $-0.23^{s, *}$ \\
\hline Feelings & $-0.53^{\mathrm{s}, * * *}$ & $-0.67^{\mathrm{s}, * * *}$ & $-0.21^{\mathrm{s}}$ \\
\hline Work & $-0.39^{\mathrm{s}, * * *}$ & $-0.44^{\mathrm{S}, * * *}$ & $-0.26^{\mathrm{s}, *}$ \\
\hline Household & $-0.37^{\text {s,*** }}$ & $-0.50^{\mathrm{s}, * * *}$ & $-0.09^{\mathrm{s}}$ \\
\hline School/study & $-0.11^{s}$ & $-0.11^{\mathrm{s}}$ & $-0.15^{\mathrm{s}}$ \\
\hline Leisure time & $-0.36^{\mathrm{s}, * *}$ & $-0.42^{\mathrm{S}, * * *}$ & $-0.26^{\mathrm{s}, *}$ \\
\hline Social activities & $-0.3 I^{\mathrm{S}, * *}$ & $-0.38^{\mathrm{s}, * * *}$ & $-0.23^{s, *}$ \\
\hline General & $-0.44^{\mathrm{s}, * * *}$ & $-0.6 I^{\mathrm{S}, * * *}$ & $-0.28^{\mathrm{s}, * * *}$ \\
\hline Sum of Q-LES-Q & $-0.53^{\mathrm{s}, * * *}$ & $-0.66^{\mathrm{s}, * * *}$ & $-0.27^{\mathrm{S}, *}$ \\
\hline
\end{tabular}

Notes: Superscript letter $S$ represent Spearman's $r$. $*_{p}<0.05, *_{p}<0.0$, and $* * * p<0.00$ I. Statistically significant data shown in bold.

Abbreviations: objCGI, (Clinical Global Impression) - objective; subjCGI, (Clinical Global Impression) - subjective; Q-LES-Q, Quality of Life Satisfaction and Enjoyment Questionnaire. 
Table 7 Correlations between quality of life and positive coping strategies

\begin{tabular}{|c|c|c|c|c|c|c|c|c|c|}
\hline Positive strategy & $\begin{array}{l}\text { Total } \\
\text { Q-LES-Q }\end{array}$ & $\begin{array}{l}\text { Physical } \\
\text { health }\end{array}$ & Feelings & Work & Household & School & Leisure & $\begin{array}{l}\text { Social } \\
\text { activities }\end{array}$ & General \\
\hline Underestimation & $0.33^{\mathrm{P}, * *}$ & $0.34^{\mathrm{P}, * *}$ & $0.33^{\mathrm{P}, * *}$ & $0.10^{s}$ & $0.30^{\mathrm{s}, * *}$ & $-0.003^{s}$ & $0.43^{\mathrm{P}, * * *}$ & $0.26^{\mathrm{P}, *}$ & $0.36^{\mathrm{P}, * *}$ \\
\hline Guilt denial & $0.3 I^{\mathrm{P}, * *}$ & $\mathbf{0 . 2 5} 5^{\mathrm{P}, *}$ & $\mathbf{0 . 2 8 ^ { \mathrm { P } , * }}$ & $0.20^{\mathrm{s}}$ & $0.40^{\mathrm{s}, * * *}$ & $-0.02^{s}$ & $0.24^{\mathrm{P}, *}$ & $0.19^{p}$ & $0.28^{\mathrm{P}, *}$ \\
\hline Diversion & $0.26^{\mathrm{P}, *}$ & $0.28^{\mathrm{P}, *}$ & $0.29^{P, * *}$ & $0.06^{\mathrm{s}}$ & $0.25^{s, *}$ & $-0.07^{s}$ & $0.2 I^{P}$ & $0.10^{P}$ & $0.28^{\mathrm{P}, *}$ \\
\hline Compensatory satisfaction & $0.19^{P}$ & $0.2 \mathrm{I}^{\mathrm{P}}$ & $0.14^{\mathrm{P}}$ & $0.02^{\mathrm{s}}$ & $0.21^{\mathrm{s}}$ & $0.02^{\mathrm{s}}$ & $0.28^{\mathrm{P}, *}$ & $0.15^{P}$ & $0.23^{\mathrm{P}, *}$ \\
\hline Situation control & $0.4 I^{\mathrm{P}, * * *}$ & $0.33^{\mathrm{P}, * *}$ & $0.34^{\mathrm{P}, * *}$ & $0.36^{\mathrm{s}, * *}$ & $0.27^{s, *}$ & $0.08^{\mathrm{s}}$ & $0.33^{\mathrm{P}, * *}$ & $0.28^{\mathrm{P}, *}$ & $0.32^{\mathrm{P}, * *}$ \\
\hline Reaction control & $0.39^{\mathrm{P}, * * *}$ & $0.35^{\mathrm{P}, * *}$ & $0.36^{\mathrm{P}, * *}$ & $0.25^{\mathrm{s}, *}$ & $0.38^{\mathrm{S}, * * *}$ & $-0.12^{s}$ & $0.27^{\mathrm{P}, *}$ & $0.20^{P}$ & $0.37^{\mathrm{P}, * * *}$ \\
\hline Positive self-instruction & $0.44^{\mathrm{P}, * * *}$ & $\mathbf{0 . 3 8} \mathbf{8}^{\mathrm{P}, * * *}$ & $0.44^{\mathrm{P}, * * *}$ & $0.24^{\mathrm{s}, *}$ & $0.29^{\mathrm{s}, * *}$ & $0.13^{s}$ & $0.35^{\mathrm{P}, * *}$ & $0.34^{\mathrm{P}, * *}$ & $0.45^{\mathrm{P}, * * *}$ \\
\hline Need for social support & $0.08^{P}$ & $0.1 I^{P}$ & $0.0 \mathrm{I}^{\mathrm{P}}$ & $-0.08^{s}$ & $0.15^{\mathrm{s}}$ & $0.03^{s}$ & $0.12^{P}$ & $0.17^{P}$ & $0.07^{P}$ \\
\hline Positive coping & $\mathbf{0 . 4 5} 5^{\mathrm{P}, * * *}$ & $0.40^{\mathrm{P}, * * *}$ & $0.4 I^{\mathrm{P}, * * *}$ & $0.25^{s, *}$ & $0.42^{\mathrm{s}, * * *}$ & $0.08^{\mathrm{s}}$ & $\mathbf{0 . 4 6} 6^{\mathrm{P}, * * *}$ & $0.28^{\mathrm{P}, *}$ & $0.43^{\mathrm{P}, * * *}$ \\
\hline
\end{tabular}

Notes: Superscript letters $P$ and S represent Pearson's $r$ and Spearman's $r$, respectively. $* p<0.05, * * p<0.0$ I, and *** $p<0.00$ I. Statistically significant data shown in bold. Abbreviation: Q-LES-Q, Quality of Life Satisfaction and Enjoyment Questionnaire.

positively related strategies were especially positive selfinstructions and situation control, which also significantly affected the physical health, feelings, work, and general QoL. None of the positive strategies was connected to the domain school of QoL (Table 7).

The strategy underestimation was most associated with leisure, guilt denial with household, diversion with feelings, situation control with work, reaction control with household, and positive self-instructions with general QoL (Table 7).

\section{Negative coping and QoL}

The QoL was negatively related to using negative coping strategies, especially resignation, which affects mainly the domains feelings, physical health, work, and general QoL. The strategy escape tendency was negatively related primarily to work and general QoL; perseveration and selfaccusation were found to affect mainly feelings (Table 8).

\section{Regression analysis}

As various factors were significantly related to the Q-LES-Q total score, a multiple regression analysis (backward stepwise regression) was performed to identify the most important factors linked to the Q-LES-Q total score as dependent variables. The independent variables which were entered in the regression analysis were positive coping strategies, negative coping strategies, sex, partnership, employment, education, subjCGI, objCGI, and the number of hospitalizations. All requested variables were entered in the analysis. The most influential factors connected with the Q-LES-Q total score were subjCGI, employment, and positive coping strategies (Table 9).

\section{Discussion}

The present study focused on the QoL and coping strategies of the patients with depression. As hypothesized, the participants with depression overuse some specific negative coping strategies, mainly escape tendency (tendency to escape from stressful situations) and resignation (give up with feelings of helplessness and hopelessness in dealing with the situation). Escape tendencies might be quite problematic for solving the stressful life events. Depressive mood is decreased or does not develop in patients who can accept the circumstances and focus on something else with a positive attitude, who concentrate on planning and finding their perspectives, and who have expectations of good things, compared to the patients with depression and anxiety who feel sadness,

Table 8 Correlations between quality of life and negative coping strategies

\begin{tabular}{|c|c|c|c|c|c|c|c|c|c|}
\hline Negative strategy & $\begin{array}{l}\text { Total } \\
\text { Q-LES-Q }\end{array}$ & $\begin{array}{l}\text { Physical } \\
\text { health }\end{array}$ & Feelings & Work & Household & School & Leisure & $\begin{array}{l}\text { Social } \\
\text { activities }\end{array}$ & General \\
\hline Active avoidance & $0.13^{P}$ & $0.06^{\mathrm{P}}$ & $0.11^{P}$ & $0.10^{5}$ & $0.13^{\mathrm{s}}$ & $-0.10^{\mathrm{s}}$ & $0.16^{\mathrm{P}}$ & $0.10^{P}$ & $0.1 I^{P}$ \\
\hline Escape tendency & $-0.30^{\mathrm{P}, * *}$ & $-0.26 \mathrm{P}, *$ & $-0.30^{\mathrm{p}, * *}$ & $-0.34^{\mathrm{s}, * *}$ & $-0.09^{s}$ & $-0.04^{\mathrm{s}}$ & $-0.16^{P}$ & $-0.10^{P}$ & $-0.32^{\mathrm{P}, * *}$ \\
\hline Perseveration & $-0.24^{\mathrm{P}, *}$ & $-0.22^{\mathrm{P}}$ & $-0.34^{\mathrm{P}, * *}$ & $-0.01^{\mathrm{s}}$ & $-0.21^{\mathrm{s}}$ & $0.04^{\mathrm{s}}$ & $-0.30^{p, * *}$ & $-0.23^{\mathrm{P}, *}$ & $-0.33^{P, * *}$ \\
\hline Resignation & $-0.43^{\mathrm{P}, * * *}$ & $-0.37^{\text {P,**** }}$ & $-0.44^{\mathrm{P}, * * *}$ & $-0.33^{\mathrm{s}, * *}$ & $-0.16^{\mathrm{s}}$ & $-0.09^{\mathrm{s}}$ & $-0.26^{\mathrm{P}, *}$ & $-0.23^{\mathrm{P}, *}$ & $-0.43^{P, * * *}$ \\
\hline Self-accusation & $-0.26^{\mathrm{P}, *}$ & $-0.18^{P}$ & $-0.3 I^{\mathrm{P}, * *}$ & $-0.19^{s}$ & $-0.16^{\mathrm{s}}$ & $0.03^{s}$ & $-0.2 \mathrm{I}^{\mathrm{P}}$ & $-0.2 \mathrm{I}^{\mathrm{P}}$ & $-0.30^{\mathrm{P}, * *}$ \\
\hline Negative coping & $-0.40^{\mathrm{P}, * * *}$ & $-0.34^{\mathrm{P}, * *}$ & $-0.55^{\mathrm{P}, * * *}$ & $-0.27^{\mathrm{s}, *}$ & $-0.21^{\mathrm{s}}$ & $0.0 \mathrm{I}^{\mathrm{s}}$ & $-0.30^{\mathrm{P}, * *}$ & $-0.26^{\mathrm{P}, *}$ & $-0.45^{\mathrm{P}, * * *}$ \\
\hline
\end{tabular}

Notes: Superscript letters $P$ and S represent Pearson's $r$ and Spearman's $r$, respectively. $* p<0.05$, ** $p<0.0$ I, and $* * * p<0.00$ I. Statistically significant data shown in bold. Abbreviation: Q-LES-Q, Quality of Life Satisfaction and Enjoyment Questionnaire. 
Table 9 Multiple regression analysis with the sum of Q-LES-Q as a dependent variable

\begin{tabular}{|c|c|c|c|c|c|c|}
\hline Model & Regressors & B & SE & $\beta$ & $t$ & Significance \\
\hline \multirow[t]{4}{*}{7} & subjCGI & -28.390 & 4.596 & -0.521 & -6.177 & 0.001 \\
\hline & Employment & -31.142 & 9.928 & -0.257 & -3.137 & 0.003 \\
\hline & Positive coping subscale & 5.937 & 1.548 & 0.317 & 3.836 & 0.001 \\
\hline & \multicolumn{6}{|c|}{ ANOVA: $F=3 \mathrm{I} .255 ; d f=66 ; p<0.00 \mathrm{I} ;$ adjusted $r$-squared $=0.579$} \\
\hline
\end{tabular}

Abbreviations: Q-LES-Q, Quality of Life Satisfaction and Enjoyment Questionnaire; SE, standard error; subjCGI, (Clinical Global Impression) - subjective; ANOVA, analysis of variance.

hopelessness, and fear. ${ }^{37}$ Resignation might be considered as a passive coping along with personal characteristics of neuroticism, and may be, according to Gutiérrez-Zotes et al, associated with the emergence of depressive symptoms. ${ }^{19}$ Also, Barata et al found that depression was positively associated with coping strategies such as avoidance, resignation, and emotional discharge, and negatively with problem-solving. ${ }^{38}$ Reflecting these findings is the question that whether the genesis of the depressive disorder itself is a reflection of resignation and attempts to escape from life situations with which the individuals concerned cannot use their coping strategies to deal them in another way. Eventually, the nature of this disorder can increase the use of these negative strategies.

Concerning the use of positive coping strategies, the patients with depressive disorder use these strategies on average, but not too much, which would be adaptive and desirable for these patients. The participants with depression use the strategies guilt denial (highlighting for themselves that they are not responsible for the situation) and reaction control (efforts to secure and maintain control of their responses). The use of guilt denial could be quite confusing because one of the symptoms of depression is self-blame and feelings of inferiority and inadequacy, which inhibit the everyday functioning of the participant. However, in practice, we often find that patients who self-blame also refuse the blame for the situation and try to find external rather than internal influences of the development of depression (physical illness, poor medication, hospitalization, medical procedures).

The positive self-instruction strategy (attribution of competence and control over the situation, including self-support) is not used much. This finding confirms the results of MillerMatero et al who found that depression was negatively related to the use of distraction and self-talk coping statements. ${ }^{39}$ The same results stem from the research of Giammanco and Gitto who found that the positive reappraisal and growth coping strategy is inversely and significantly correlated with anxiety and depression..$^{40}$ That is why, it might be important in practice to strengthen this strategy and further promote its use in patients with depression.
The QoL of the patients with depression was decreased in comparison to healthy population standards, as we expected and as documented in many other studies. ${ }^{3,26,41,42}$ It is possible that after the improvement of the mental state and the current severity of psychopathology, QoL will be higher. Moreover, the participants in this sample were not in an acute phase of the depressive disorder, but they have been treated with antidepressants. This finding confirms the results of Ishak et al who detected that during treatments with antidepressants, the QoL improved considerably, but did not cross over 30\%-50\% level, and thus remained at below average or average level compared to the QoL of the controls. ${ }^{9}$ The reduced QoL in patients with depression in remission can lead quickly to recurrence of their disease.

There is the question of how perceptions of the QoL change over time. Whether QoL is a changeable variable affecting only the current mental state of the participant or a stable variable remains to be seen. We found that the actual subjective and objective severity of the disorder negatively correlated with QoL, but not with other demographic factors (such as age, the onset of the disorder, duration), except the number of hospitalizations. These findings are in agreement with Berlim and Fleck who found that the degree of disturbance in $\mathrm{QoL}$ is proportional to the severity of depressive symptoms. ${ }^{8}$ The higher number of hospitalizations may be related to the feeling of being more severely mentally ill, but it is just a reflection, unverified by this study.

Another aim of the present study was to examine the relationship between the coping strategies and the QoL. We hypothesized that using positive coping strategies may have a positive association with the QoL, and we confirmed this hypothesis. The strategies positive self-instructions and situation control, which correlate with many domains of QoL, seem to be essential to help patients reinforce the use of these coping strategies since they affect the core domain functioning in everyday life and provide a sense that they are doing better.

Negative coping strategies, especially resignation and escape tendency, were negatively related with the overall QoL. In the case that the patients with depression resigned 
to find a solution to their stressful life situations, are unable to deal with them, and try to escape from them, there is an adverse impact on the overall perception of their QoL and their present and future perspectives. These research results are supported by other studies..$^{40,43}$ Generally speaking, the more the patients with depression use negative coping strategies, the more they deepen their sense of frustration and failure to cope with their lives, function, and fulfill essential roles according to their QoL. These negative coping strategies can hypothetically deepen their depression, and depression may again affect the perception of their QoL that would be probably higher without depression. However, this cross-sectional study is not able to answer any causality question.

The last goal of this study was to examine the connections between demographic and clinical variables, coping strategies, and QoL as a dependent variable. The regression analysis showed that the overall QoL was mainly influenced by the subjective severity of the disorder, being un/employed, and use of positive coping strategies. The participants who felt being more severely mentally ill assessed their QoL as worse, so the actual perception of psychopathology is important. Having a job or being unemployed is probably another factor that has an impact on a patient's satisfaction with life. The patients who use more positive coping strategies and can support themselves in stressful life situations also have higher QoL; that is why, it is important in clinical practice to reduce the severity of psychopathology by pharmacological and psychotherapeutic options and encourage the use of adaptive coping strategies that would help the patients adaptively cope with difficult life period in which a depressive disorder occurs.

\section{Limitations}

The study has several limitations. Primarily, participants completed the self-report scales and questionnaires, which may be affected by their current state and their willingness to cooperate. The questionnaires were quite long that participants may have been tired. Also, the small sample size is a limitation of this study. The severity of the disorder was assessed only by the global clinical evaluation, using no symptom-specific objective assessment instruments.

\section{Conclusion}

Depressive disorders are associated with reduced QoL and the use of specific coping strategies, especially maladaptive overuse of negative coping strategies. Coping strategies have an essential role in solving and coping with a depressive illness, but they can also be a predictor of depressive disorders and lower QoL. Interventions aimed at increasing the use of the adaptive coping strategies may help to cope with stressful life situations and also improve the patient's mood and QoL. For example, cognitive behavioral therapy (CBT) can work very well and efficiently with rethinking, and change the perception of the situation where depressed patients may feel powerless to resolve and resort to the situation by themselves. CBT methods can help to change the way of thinking about the situation, and in the transformation of its importance and its impact, and the creation of a more realistic view of the possibilities of solving the situation without the need to deepen depression (according to the cognitive model by Aaron Beck). ${ }^{44}$ Concentrating on the support and the use of adaptive coping strategies, it may become a useful tool in prevention and control of the depressive disorders.

\section{Acknowledgments}

The authors thank MUDr. Jiří Rozkoš from Prostějov, MUDr. Jan Flídr from Kralupy nad Vltavou, MUDr. Jana Matějková from Prague, MUDr. Simona Papežová from Prague, MUDr. Pavel Tautermann from Prague, MUDr. Markéta Zemanová from Havlíčkův Brod, MUDr. Markéta Dobrá from Hrabyně, MUDr. Zuzana Kozáková from Trutnov (association RIAPS), MUDr. Tibor Miklóš from Prague, MUDr. Michaela Zapletalová from Chomutov, MUDr. Jana Novosadová from Blansko, MUDr. Jiří Trska from Týn nad Vltavou, MUDr. Zdeněk Holoubek from Nymburk, MUDr. Iva Ondráčková from Prague, MUDr. Andrea Bryčková from Hořice, MUDr. Jindřiška Masnerová from Beroun, MUDr. Petr Pastucha from Prostějov and MUDr. Hana Lemanová from Brno for their willing cooperation.

\section{Disclosure}

The authors report no conflicts of interest in this work.

\section{References}

1. World Health Organization. Measuring Quality of Life: The World Health Organization Quality of Life Instruments (The WHOQOL-100 and the WHOQOL-BREF). Geneva: Division of Mental Health; 1997.

2. Wells KB, Stewart A, Hays RD, et al. The functioning and well-being of depressed patients. Results from the Medical Outcomes Study. JAMA. 1989;262(7):914-919.

3. Papakostas G, Petersen T, Mahal Y, Mischoulon D, Nierenberg AA, Fava M. Quality of life assessments in major depressive disorder: a review of the literature. Gen Hosp Psychiatry. 2004;26(1):13-17.

4. Herrman H, Patrick DL, Diehr P, et al. Longitudinal investigation of depression outcomes in primary care in six countries: the LIDO study. Functional status, health service use and treatment of people with depressive symptoms. Psychol Med. 2002;32(5):889-902.

5. Greer TL, Kurian BT, Trivedi MH. Defining and measuring functional recovery from depression. CNS Drugs. 2010;24(4):267-284. 
6. Steiner AJ, Boulos N, Mirocha J, Wright SM, Collison KL, IsHak WW. Quality of life and functioning in comorbid posttraumatic stress disorder and major depressive disorder after treatment with citalopram monotherapy. Clin Neuropharmacol. 2016;40(1):16-23.

7. Trivedi MH, Rush AJ, Wisniewski SR, et al. Factors associated with health-related quality of life among outpatients with major depressive disorder: a STAR*D report. J Clin Psychiatry. 2006;67(2):185-195.

8. Berlim MT, Fleck MPA. Quality of life and major depression. In: Ritsner MS, Awad AG, editors. Quality of Life Impairments in Schizophrenia, Mood and Anxiety Disorder. New York, NY: Springer; 2007:241-252.

9. Ishak WW, Mirocha J, James D, et al. Quality of life in major depressive disorder before/after multiple steps of treatment and one-year follow-up. Acta Psychiatr Scand. 2015;131(1):51-60.

10. Marquez-Arrico JE, Benaiges I, Adan A. Strategies to cope with treatment in substance use disorder male patients with and without schizophrenia. Psychiatry Res. 2015;228(8):752-759.

11. Skinner E, Edge K, Altman J, Sherwood H. Searching for the structure of coping: a review and critique of category systems for classifying ways of coping. Psychol Bull. 2003;129(2):216-269.

12. Holahan CJ, Moos RH. Risk, resistance, and psychological distress: a longitudinal analysis with adults and children. J Abnorm Psychol. 1987;96(1):3-13.

13. Lecic-Tosevski D, Vukovic O, Stepanovic J. Stress and personality. Psychiatriki. 2011;22(4):290-297.

14. Folkman S, Lazarus RS, Dunkel-Schetter C, DeLongis A, Gruen RJ. Dynamics of a stressful encounter: cognitive appraisal, coping, and encounter outcomes. J Pers Soc Psychol. 1986;50(5):992-1003.

15. CompasBE, Connor-SmithJK, Saltzman H, Thomsen AH, Wadsworth ME. Coping with stress during childhood and adolescence: problems, progress, and potential in theory and research. Psychol Bull. 2001; 127(1):87-127.

16. Snow DL, Swan SC, Raghavan C, Connell CM, Klein I. The relationship of work stressors, coping and social support to psychological symptoms among female secretarial employees. Work Stress. 2003; 17(3):241-263.

17. Van Berkel $\mathrm{H}$. The relationship between personality, coping styles and stress, anxiety and depression. 2014. Available from: https://ir.canterbury. ac.nz/handle/10092/2612. Accessed December 10, 2014.

18. Lin HS, Probst JC, Hsu YC. Depression among female psychiatric nurses in southern Taiwan: main and moderating effects of job stress, coping behaviour and social support. J Clin Nurs. 2010;19(15-16): 2342-2354.

19. Gutiérrez-Zotes A, Labad J, Martín-Santos R, et al. Coping strategies for postpartum depression: a multicentric study of 1626 women. Arch Womens Ment Health. 2016;19(3):455-461.

20. Janke W, Erdmann G. SVF 78: eine Kurzform des Stressverarbeitungsfragebogen SVF 120 [SVF 78: A Short Form of the Stress Processing Questionnaire SVF 120]. Gottingen: Hogrefe Verlag für Psychologie; 2002. German.

21. Roohafza H, Feizi A, Afshar H, et al. Path analysis of relationship among personality, perceived stress, coping, social support, and psychological outcomes. Psychiatriki. 2011;22(4):290-297.

22. Vollrath M, Torgersen S. Personality types and coping. Pers Individ Dif. 2000;29:367-378.

23. De Leval N. The three time dimensions synoptic scale (3TSS) for depressive population. Qual Life News Lett. 2001;26:15-16.

24. Sheshtawy EA. Coping with stress and quality of life in schizophrenic patients. Asian J Psychiatr. 2011;4(1):51-54.

25. Kizılırmak M, Demir S. Investigation of depression and quality of life in nurses working in hospitals. TAF Prevent Med Bull. 2016; 15(2):132-140.
26. Burger PH, Neumann C, Ropohl A, Paulsen F, Scholz M. Development of depression and deterioration in quality of life in German dental medical students in preclinical semesters. Ann Anat. 2016;2(16):940-960.

27. Christensen MV, Kessing LV. Clinical use of coping in affective disorder, a critical review of the literature. Clin Pract Epidemiol Ment Health. 2005;1(1):20.

28. Brenner K, St-Hilaire A, Liu A, Laplante DP, King S. Cortisol response and coping style predict the quality of life in schizophrenia. Schizophr Res. 2011;128(1-3):23-29.

29. World Health Organization. The ICD-10 Classification of Mental and Behavioral Disorders: Diagnostic Criteria for Research. Geneva: World Health Organization; 1993.

30. Svancara J. Coping Strategies. Prague: Testcentrum; 2003.

31. Ritsner M, Kurs R, Gibel A, Ratner Y, Endicott J. Validity of an abbreviated Quality of Life Enjoyment and Satisfaction Questionnaire (Q-LES-Q-18) for schizophrenia, schizoaffective, and mood disorder patients. Qual Life Res. 2005;14:1693-1703.

32. Müllerova $H$. Transcultural transmission and validation of the quality life questionnaire Q-LES-Q. Psychiatrie. 2001;5:80-87.

33. Endicott J, Nee J, Harrison W, Blumenthal R. Quality of Life Enjoyment and Satisfaction Questionnaire: a new measure. Psychopharmacol Bull. 1993;29(2):321-326.

34. Guy W. ECDEU Assessment Manual for Psychopharmacology. Rockville, MD: US Department of Health, Education, and Welfare; 1976.

35. Kadouri A, Corruble E, Falissard B. The improved Clinical Global Impression Scale (ICGI): development and validation in depression. BMC Psychiatry. 2007;7:7.

36. EMEA. 2002. Available from: http://www.ema.europa.eu/docs/en_GB/ document_library/Scientific_guideline/2009/09/WC500002874.pdf Accessed March 20, 2009.

37. Kulpa M, Ziętalewicz U, Kosowicz M, Stypuła-Ciuba B, Ziółkowska P. Anxiety and depression and cognitive coping strategies and health locus of control in patients with ovary and uterus cancer during anticancer therapy. World J Psychiatry. 2016;6(2):248-256.

38. Barata A, Gonzalez BD, Sutton SK, et al. Coping strategies modify risk of depression associated with hematopoietic cell transplant symptomatology. Cancer. 2016;122(3):2110-2116.

39. Miller-Matero LR, Chipungu K, Martinez S, Eshelman A, Eisenstein D. How do I cope with pain? Let me count the ways: awareness of pain coping behaviors and relationships with depression and anxiety. J Health Psychol. 2016;22(1):19-27.

40. Giammanco MD, Gitto L. Coping, uncertainty and health-related quality of life as determinants of anxiety and depression on a sample of hospitalized cardiac patients in Southern Italy. Qual Life Res. 2016;25(11):2941-2956.

41. De Lima Silva V, de Medeiros CA, Guerra GC, et al. Quality of life, integrative community therapy, family support, and satisfaction with health services among elderly adults with and without symptoms of depression. Neuropsychiatr Dis Treat. 2014;10:811-816.

42. Woo JM, Jeon HJ, Noh E, et al. Importance of remission and residual somatic symptoms in health related quality of life among outpatients with major depressive disorder: a cross-sectional study. J Psychosom Res. 2015;78(1):25-33.

43. Nipp RD, El-Jawahri A, Fishbein JN, et al. The relationship between coping strategies, quality of life, and mood in patients with incurable cancer. Cancer. 2016;122(13):2110-2116.

44. Beck AT. The Evolution of the cognitive model of depression and its neurobiological correlates. Am J Psychiatry. 2008;165(8):969-977. 


\section{Publish your work in this journal}

Neuropsychiatric Disease and Treatment is an international, peerreviewed journal of clinical therapeutics and pharmacology focusing on concise rapid reporting of clinical or pre-clinical studies on a range of neuropsychiatric and neurological disorders. This journal is indexed on PubMed Central, the 'PsycINFO' database and CAS,

and is the official journal of The International Neuropsychiatric Association (INA). The manuscript management system is completely online and includes a very quick and fair peer-review system, which is all easy to use. Visit http://www.dovepress.com/testimonials.php to read real quotes from published authors.

Submit your manuscript here: http://www.dovepress.com/neuropsychiatric-disease-and-treatment-journal 